\title{
The effect of nitric oxide inhibitors and s-nitrosothiols on hemodynamic parameters in an animal model
}

This article was published in the following Dove Press journal:

Open Access Animal Physiology

22 February 201I

Number of times this article has been viewed

\author{
Sophia Bryan' \\ Ruby Alexander-Lindo' \\ Tara Dasgupta ${ }^{2}$ \\ Donovan McGrowder ${ }^{3}$ \\ 'Department of Basic Medical \\ Sciences, Faculty of Medical Sciences, \\ ${ }^{2}$ Department of Chemistry, Faculty \\ of Pure and Applied Sciences, \\ ${ }^{3}$ Department of Pathology, Faculty \\ of Medical Sciences, University of the \\ West Indies, Kingston, Jamaica
}

Background: Nitric oxide (NO) is becoming an increasingly important signaling molecule implicated in a growing number of physiological and pathophysiological processes. We sought to test the hypothesis that co-administration of S-nitro-N-acetylpenicillamine (SNAP) or S-nitrosocaptopril (CapSNO) with $\mathrm{N}^{\mathrm{G}}$-methyl-L-arginine ester (L-NAME) or $\mathrm{N}^{\mathrm{G}}$-methylL-arginine acetate (L-NMMA) may reverse the elevated systolic, diastolic, and mean arterial pressures caused by the administration of L-NAME or L-NMMA only.

Materials and methods: Blood pressure was measured using the CODA 6 machine. The hemodynamic parameters systolic blood pressure (SBP), diastolic blood pressure (DBP), mean arterial pressure (MAP) and heart rate (HR) were determined for each rat group. There was intravenous (IV) administration of the control $(0.3 \mathrm{~mL}$, saline) or dosage of $12.5 \mathrm{mg} / \mathrm{kg}$ body weight of SNAP or CapSNO via IV.

Results: In CapSNO and L-NAME-treated rats, CapSNO significantly decreased SBP from $131.12 \pm 4.29 \mathrm{mmHg}$ to $121.42 \pm 4.24 \mathrm{mmHg}$ after 5 minutes $(P<0.0001)$, and then L-NAME (administered at $\mathrm{t}=5 \mathrm{~min}$ ) increased SBP to $165.29 \pm 6.79 \mathrm{mmHg}$ at 10 minutes $(P<0.05)$. In SNAP and L-NAME-treated rats, SNAP significantly decreased SBP from $135.86 \pm 2.84 \mathrm{mmHg}$ to $106.98 \pm 1.99 \mathrm{mmHg}(P<0.0001)$ after 5 minutes, and L-NAME increased SBP to $146.18 \pm 3.19 \mathrm{mmHg}$ after 25.0 minutes $(P<0.05)$. In rats treated with SNAP and L-NAME, SNAP decreased DBP to $74.98 \pm 2.49 \mathrm{mmHg}(P<0.0001)$ after 5 minutes while L-NAME increased DBP to $105.01 \pm 2.60 \mathrm{mmHg}$ after 25 minutes $(P<0.05)$. In SNAP and L-NAME treated group there was an increase in HR after the administration of SNAP ( $486.60 \pm 30.82$ at 0 minutes to $555.66 \pm 32.37$ beats $\min ^{-1}$ at 5 minutes; $P<0.0001$ ), followed by a decrease in HR to $336.90 \pm 17.48$ beats $\mathrm{min}^{-1}$ at 25 minutes $(P<0.05)$ after the administration of L-NAME (at $\mathrm{t}=5 \mathrm{~min}$ ).

Conclusion: The data suggest that the actions of L-NAME and L-NMMA reversed the effects of NO released from SNAP or CapSNO. These drugs could be beneficial in the control of blood pressure in hypertensive patients.

Keywords: nitric oxide, $\mathrm{N}^{\mathrm{G}}$-methyl-L-arginine ester, $\mathrm{N}^{\mathrm{G}}$-methyl-L-arginine acetate, S-nitro-N-acetylpenicillamine, blood pressure, S-nitrosocaptopril

\section{Introduction}

Nitric oxide (NO) is a signaling molecule that is involved in a variety of physiological and pathological cellular processes in various tissues including vasculature, central nervous system, and skeletal muscle. ${ }^{1}$ Nitric oxide is synthesized as a product of the conversion of its physiological precursor, L-arginine, to L-citrulline, a reaction which is catalyzed by a family of enzymes known as the NO synthases (NOS). Three isoforms of NOS have been identified in mammalian tissues, namely, NOS 1 (neuronal 
NOS, nNOS), NOS 2 (inducible NOS, iNOS) and NOS 3 (endothelial NOS, eNOS). ${ }^{2}$ In contrast to the activities of nNOS and eNOS, which are tightly regulated by calciumdependent calmodulin binding, iNOS does not require calcium ion or post-translational modification for its activity. Therefore, iNOS expression is associated with prolonged, exaggerated NO generation up to more than 1000 -fold compared with nNOS and eNOS. ${ }^{3,4}$

The NOS inhibitors are guanidino amino acids which act competitively at the NOS active site. These include $\mathrm{N}^{\mathrm{G}}$-nitro-L-arginine (L-NNA), $\mathrm{N}^{\mathrm{G}}$-methyl-L-arginine ester (L-NAME, a methyl ester pro-drug that is activated to become L-NNA) and $\mathrm{N}^{\mathrm{G}}$-methyl-L-arginine acetate (L-NMMA). L-NMMA, L-NNA, and L-NAME act as competitive, stereospecific inhibitors of NOS synthase and in some cases irreversible inhibitors of both the constitutive and inducible NO synthase. However, L-NMMA and L-NAME are relatively more selective for the constitutive isoforms and compete for the substrate, L-arginine, thereby inhibiting the formation of NO. ${ }^{5,6}$ L-NMMA and L-NAME are important in the regulation of regional vascular conductance in conscious animals. ${ }^{78}$ Vallance and colleagues found that arterial infusion of L-NMMA caused a 50\% fall in basal blood flow. ${ }^{9}$ Further, Rees et al reported that L-NAME was about 10 -fold more potent than L-NMMA in increasing blood pressure. ${ }^{10}$

In contrast, $\mathrm{NO}$ donors are drugs that generate $\mathrm{NO}$ through mechanisms that are independent of NOS. Commonly used agents are the organic nitrates (eg, glyceryl trinitrate [GTN], isosorbide dinitrate [ISDN]), sodium nitroprusside (SNP), sydnonimines (eg, molsidomine [SIN-1]), s-nitrosothiols (eg, S-nitrosoglutathione [GSNO], S-nitroso-N-acetylpenicillamine [SNAP]), NONOates (eg, SPERMINE-NONOate, DETA-NONOate), and hybrid donors (eg, nitroaspirins, nicorandil). S-nitroso$\mathrm{N}$-acetylpenicillamine and S-nitrosocaptopril (CapSNO) are examples of synthetic s-nitrosothiols which have been used extensively in research. S-nitroso-N-acetylpenicillamine has been shown to have a powerful vasodilatory effect and antiplatelet activity in the cardiovascular system ${ }^{11}$ and was found to significantly reduce mean arterial pressure in animals. ${ }^{12}$ However, its use as an anti-platelet agent is limited by its intense vasodilatory and hence hypotensive effects. CapSNO is a S-nitroso derivative and a hybrid compound of both captopril and NO. ${ }^{13}$ As a unique compound, it has properties of both a direct nitrovasodilator and an angiotensin converting enzyme (ACE) inhibitor and is not cross-tolerant with GTN. ${ }^{14}$ CapSNO has been found to dilate coronary arteries by virtue of its NO moiety and is a potential anti-anginal drug. ${ }^{15}$
Experimental evidence from animal studies suggested that SNAP had a beneficial effect of reducing blood pressure, although this was associated with decreased glucose tolerance. ${ }^{16}$ We sought to test the hypothesis that co-administration of L-NAME or L-NMMA with SNAP or CapSNO may reverse the elevated systolic, diastolic, and mean arterial pressure caused by the administration of L-NAME or L-NMMA only. Therefore, this study examined the effects of L-NMMA and L-NAME on hemodynamic parameters such as systolic, diastolic, mean arterial pressure, and heart rate in normotensive rats. The study also sought to investigate the co-administration of SNAP or CapSNO with L-NAME or L-NMMA on these hemodynamic parameters.

\section{Materials and methods}

\section{Animals}

Sprague-Dawley rats (250-350 g) were obtained from the Basic Medical Sciences Animal House, The University of the West Indies, Mona and were housed under the supervision of the attendants present. The rats were fed a diet of Purina Laboratory Chow and water administered ad libitum. A total of 44 rats were used for this study, and 6 to 8 rats were used for each set of experiments. All procedures were approved and conducted in accordance with the guidelines of the University Hospital of the West Indies, The University of West Indies and the Faculty of Medical Sciences (UHWI/ UWI/FMS) Ethics Committee.

\section{Sample preparation}

A dosage of $30 \mathrm{mg} \mathrm{kg}^{-1}$ body weight (BW) of L-NAME and L-NMMA (Sigma-Aldrich, St. Louis, MO, USA) were used for analysis. ${ }^{17} \mathrm{~L}-\mathrm{NAME}$ and L-NMMA were dissolved in saline $(0.3 \mathrm{~mL} ; 0.9 \% \mathrm{NaCl})$ just before the beginning of the analysis. The solution was then administered into the tail vein of the rat immediately after the basal reading was taken for observation of the effect of the NOS inhibitors only on hemodynamic parameters.

\section{Hemodynamic studies}

Blood pressure was measured via a non-invasive method, using the CODA 6 machine (Kent Scientific Corporation, Torrington, CT, USA). This machine enabled measurement of systolic blood pressure (SBP), diastolic blood pressure (DBP), mean arterial pressure (MAP) and heart rate (HR) (in beats per minute) of each rat. ${ }^{18}$ The CODA system uses volume pressure recording (VRP) to measure blood pressure in mice and rats. The VRP correlates $99 \%$ with direct blood pressure and telemetry. Blood pressure was non-invasively measured 
by determining the tail blood volume with a volume pressure recording sensor and an occlusion tail-cuff. Acclimatization readings were taken (which were not used in the final data analysis), followed by the acquisition of basal readings $(\mathrm{t}=0 \mathrm{~min})$. After basal readings were obtained, the machine was set to pause briefly to allow for intravenous administration of the control ( $0.3 \mathrm{~mL}$, saline) or dosage of $12.5 \mathrm{mg} / \mathrm{kg} \mathrm{BW}$ of SNAP or CapSNO (Sigma-Aldrich, St. Louis, MO, USA), ${ }^{17}$ via IV and then allowed to run for a further 5 minutes. At the 5 -minute interval $(\mathrm{t}=5 \mathrm{~min})$, the machine was then set to pause briefly and immediately after which L-NAME, or L-NMMA were separately administered via IV at a dose of $30 \mathrm{mg} \mathrm{kg}^{-1}$ $\mathrm{BW}$. The machine was then allowed to continue to run uninterrupted for a further 20 minutes with blood pressure readings taken at 5-minute intervals by the machine until 5 cycles had been completed. Twenty-five minutes was done to ensure sufficient time to observe the effects of the drugs administered and to minimize undue stress to the animals in the study.

\section{Statistical analysis}

Each data point was expressed as mean \pm standard error of the mean (SEM). The significance between groups and within groups was determined using the $t$ test or the 2-way ANOVA with $P \leq 0.05$ considered to be significant.

\section{Results}

In L-NAME-treated rats, there was a significant increase in SBP from $142.75 \pm 5.75 \mathrm{mmHg}$ to $185.12 \pm 2.00 \mathrm{mmHg}$ $(P<0.0001)$ after 5 minutes followed by a decrease to $143.58 \pm 3.25 \mathrm{mmHg}$ at the 15 -minute interval. In L-NMMA-treated rats there was a significant increase in SBP from $137.23 \pm 2.43 \mathrm{mmHg}$ to $146.48 \pm 2.37 \mathrm{mmHg}$ after 5 minutes followed by a decrease to $125.32 \pm 1.71 \mathrm{mmHg}$ at 25 minutes (Figure 1). The increase in SBP was significantly higher in rats treated with L-NAME $(185.12 \pm 2.00 \mathrm{mmHg})$ compared with L-NMMA $(146.48 \pm 2.37 \mathrm{mmHg} ; P<0.00016)$ and saline $(113.00 \pm 3.13 \mathrm{mmHg} ; P<0.00012)$ after 5 minutes.

In CapSNO and L-NAME-treated rats, administration of CapSNO significantly decreased SBP to its lowest value of $121.42 \pm 4.24 \mathrm{mmHg}$ after 5 minutes $(P<0.0001)$. The administration of L-NAME (at $\mathrm{t}=5 \mathrm{~min}$ ) resulted in fluctuations in the SBP with a sharp increase to $165.29 \pm 6.79 \mathrm{mmHg}$ at 10 minutes $(P<0.05)$ and a gradual decrease to $162.50 \pm 2.76 \mathrm{mmHg}$ at 25.0 minutes. In SNAP and L-NAMEtreated rats, administration of SNAP caused a significant decrease in SBP to its lowest value of $106.98 \pm 1.99 \mathrm{mmHg}$ $(P<0.0001)$ after 5 minutes. Administration of L-NAME (at $\mathrm{t}=0 \mathrm{~min}$ ) caused a gradual increase to $146.18 \pm 3.19 \mathrm{mmHg}$ after 25-minutes. In SNAP and L-NMMA-treated rats, SNAP decreased SBP to $126.29 \pm 2.51 \mathrm{mmHg}(P<0.0001)$ after 5 minutes (Figure 1).

L-NAME significantly increased the DBP to $134.16 \pm 2.85 \mathrm{mmHg}(P<0.0001)$ after 5 minutes, followed by a decrease to $110.48 \pm 3.15 \mathrm{mmHg}$ after 15 minutes, then an increase to $128.86 \pm 1.62 \mathrm{mmHg}(P<0.05)$ after $25 \mathrm{~min}$ utes (Table 1). In rats treated with SNAP and L-NAME, SNAP decreased the SBP to $74.98 \pm 2.49 \mathrm{mmHg}(P<0.0001)$ 5 minutes after the administration of SNAP. On administration of L-NAME the DBP increased to $105.01 \pm 2.60 \mathrm{mmHg}$ at 25 minutes $(P<0.05)$. The DBP in rats treated with SNAP and L-NAME $(89.15 \pm 4.69 \mathrm{mmHg})$ was significantly lower than in rats treated with CapSNO and L-NAME $(133.26 \pm 6.15 \mathrm{mmHg} ; P=0.000011)$ after 10 minutes (Table 1). In SNAP and L-NMMA-treated rats, the DBP of $112.84 \pm 2.82 \mathrm{mmHg}$ after 20 minutes, was significantly higher than saline control $(86.00 \pm 1.50 \mathrm{mmHg} ; P=0.0019)$.

In examining the MAP, L-NAME $(150.82 \pm 2.32 \mathrm{mmHg})$ exhibited a significant hypertensive effect compared with saline $(101.75 \pm 2.72 \mathrm{mmHg}$ at 5 minutes; $P<0.0001)$. There was a significant reduction at 15 minutes where rats treated with L-NAME had MAP of $121.22 \pm 3.05 \mathrm{mmHg}$ which was significantly higher than in those treated with L-NMMA (96.22 $\pm 1.24 \mathrm{mmHg} ; P<0.0001$; Figure 2). The decrease in MAP in rats treated with SNAP and L-NAME was more significant after 5 minutes $(85.29 \pm 2.24 \mathrm{mmHg})$ than in those treated with CapSNO and L-NAME (100.96 $\pm 3.80 \mathrm{mmHg}$; $P=0.00068)$. Further, the MAP for rats treated with CapSNO and L-NAME (143.61 $\pm 6.33 \mathrm{mmHg})$ was significantly higher than in those treated with SNAP and L-NAME $(100.64 \pm 4.58 \mathrm{mmHg} ; P<0.0001)$ after 10 minutes (Figure 2).

A reduction in HR from $433.70 \pm 10.08$ beats $\mathrm{min}^{-1}$ at 0 minutes to $362.46 \pm 15.81$ beats $\mathrm{min}^{-1}$ at 5 minutes $(P<0.05)$ was observed in rats treated with L-NAME. This was followed by an increase to $405.21 \pm 22.75$ beats $\mathrm{min}^{-1}$ after 10 minutes (Table 2). A similar trend was observed in rats treated with L-NMMA where the HR decreased from $411.68 \pm 12.72$ to $363.76 \pm 11.75$ beats $\min ^{-1}(P<0.05)$ after 5 minutes followed by an increase to $414.73 \pm 24.50$ beats $\mathrm{min}^{-1}$ after 15 minutes $(P<0.05)$. In the SNAP and L-NAME treated group there was an increase in HR after the administration of SNAP (486.60 \pm 30.82 at 0 minutes to $555.66 \pm 32.37$ beats $\mathrm{min}^{-1}$ at 5 minutes; $\left.P<0.0001\right)$. This was followed by a gradual decrease in HR to $336.90 \pm 17.48$ beats $\mathrm{min}^{-1}$ at $25 \mathrm{~min}$ $(P<0.05)$ after the administration of L-NAME (Table 2$)$. 


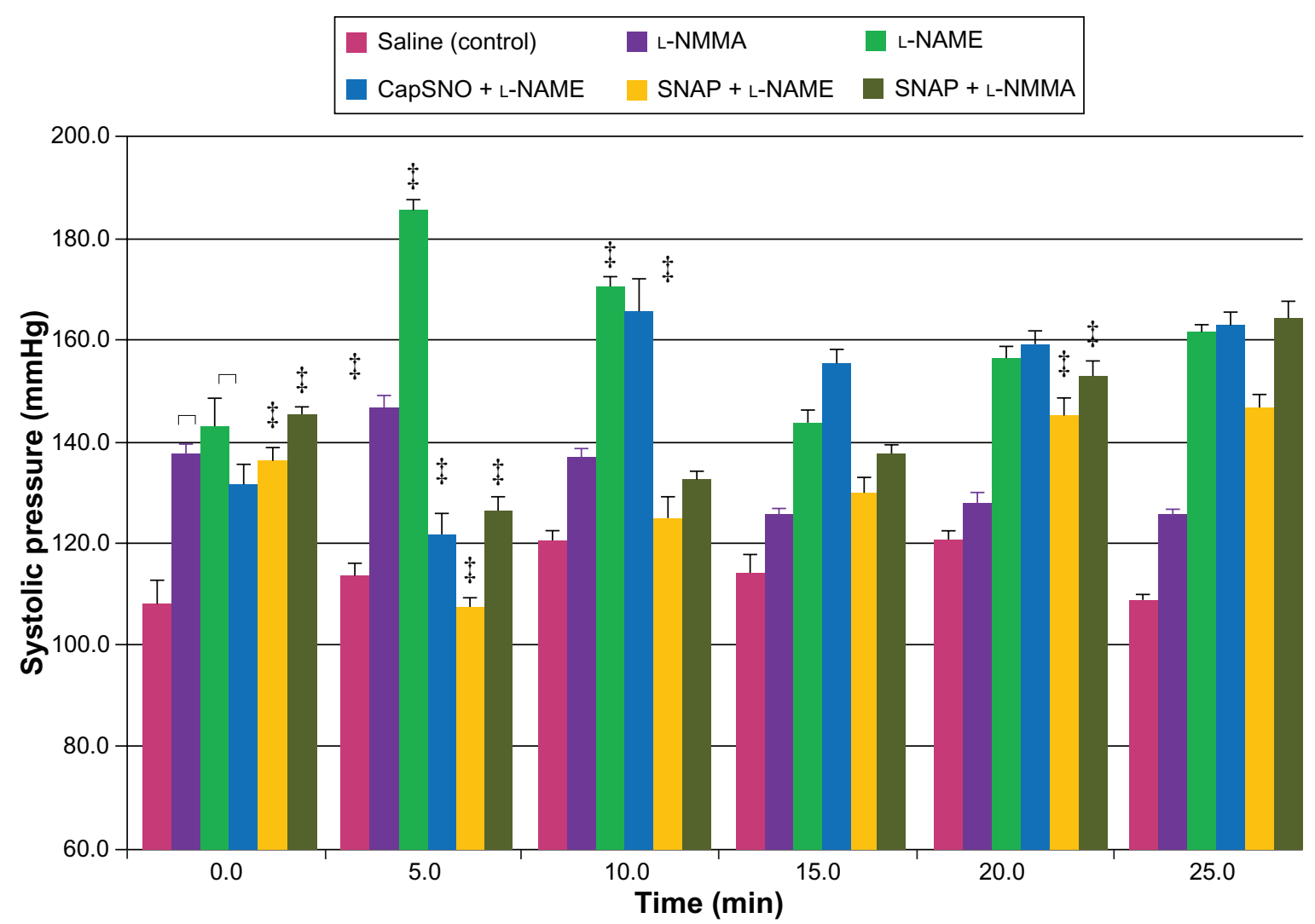

Figure I The effect of SNAP, CapSNO, L -NAME, and L-NMMA on systolic blood pressure.

Note: $¥$ Significant differences between values at time point given and $t=0$ or $t=5.0 \mathrm{~min}$; for full names of chemical compounds see Introduction.

\section{Discussion}

Nitric oxide (NO) is an important mediator with a wide variety of biological functions including the control of blood vessel tone and neurotransmission. Analysis of the hemodynamic data revealed that SNAP and CapSNO reduced systolic, diastolic, and mean arterial pressures in normotensive rats. According to the data obtained, SNAP caused the most significant decrease in blood pressure and was shown to be more potent than CapSNO. The blood pressurelowering effect of SNAP correlates with findings proposed by Shaffer et al who showed that CapSNO administered at a dosage of $12.5 \mathrm{mg} / \mathrm{kg}$ BW could significantly decrease blood pressure in anesthetized and conscious rats when compared with captopril-treated rats. ${ }^{13}$ The findings from this study are in congruence with similar findings in which, as we have indicated, GSNO and SNAP had beneficial effects based on their reduction of blood pressure in normotensive dogs. ${ }^{12,16}$ GSNO and SNAP are potent vasodilators and are able to cause a significant decrease in DBP and SBP. ${ }^{19,20}$ The mechanism involves the release of the NO from the s-nitrosothiols leading to the activation of soluble guanylate cyclase and a decrease in $\mathrm{Ca}^{2+}$ concentration..$^{21,22}$

Table I The effect of SNAP, CapSNO, L-NAME, and L-NMMA on diastolic blood pressure

\begin{tabular}{lllllll}
\hline $\begin{array}{l}\text { Time } \\
(\boldsymbol{m i n})\end{array}$ & Saline & \multicolumn{2}{l}{ Diastolic blood pressure $(\mathrm{mmHg})$} & & \\
\cline { 2 - 7 } & & L-NAME & L-NMMA & $\begin{array}{l}\text { CapSNO + } \\
\text { L-NAME }\end{array}$ & $\begin{array}{l}\text { SNAP + } \\
\text { L-NAME }\end{array}$ & $\begin{array}{l}\text { SNAP + } \\
\text { L-NMMA }\end{array}$ \\
\hline 0.0 & $97.25 \pm 3.2$ & $92.59 \pm 5.49$ & $90.70 \pm 2.19$ & $99.36 \pm 4.16$ & $91.86 \pm 3.43$ & $93.79 \pm 1.93$ \\
5.0 & $97.00 \pm 2.5$ & $134.16 \pm 2.85^{\ddagger}$ & $95.75 \pm 1.47$ & $91.28 \pm 3.81$ & $74.98 \pm 2.49^{\ddagger}$ & $94.23 \pm 2.41$ \\
10.0 & $94.50 \pm 1.5$ & $123.13 \pm 1.79$ & $93.60 \pm 1.63$ & $133.25 \pm 6.15^{\ddagger *}$ & $89.15 \pm 4.69^{*}$ & $97.62 \pm 1.88$ \\
15.0 & $89.75 \pm 2.3$ & $110.48 \pm 3.15$ & $82.14 \pm 1.48$ & $121.77 \pm 2.83$ & $91.68 \pm 2.80$ & $103.55 \pm 3.05$ \\
20.0 & $86.00 \pm 1.50^{*}$ & $124.95 \pm 2.00^{\ddagger}$ & $82.58 \pm 2.11$ & $127.59 \pm 2.75^{\ddagger}$ & $102.04 \pm 2.96^{\ddagger}$ & $112.84 \pm 2.82^{\ddagger}$ \\
25.0 & $84.50 \pm 1.30$ & $128.86 \pm 1.62$ & $84.10 \pm 1.78$ & $130.05 \pm 3.01$ & $105.01 \pm 2.60$ & $121.63 \pm 3.21$ \\
\hline
\end{tabular}

Notes: :Significant differences between values at time point given and $\mathrm{t}=0$ or $\mathrm{t}=5.0 \mathrm{~min}$; *Significant differences between the groups; for full names of chemical compounds see Introduction. 


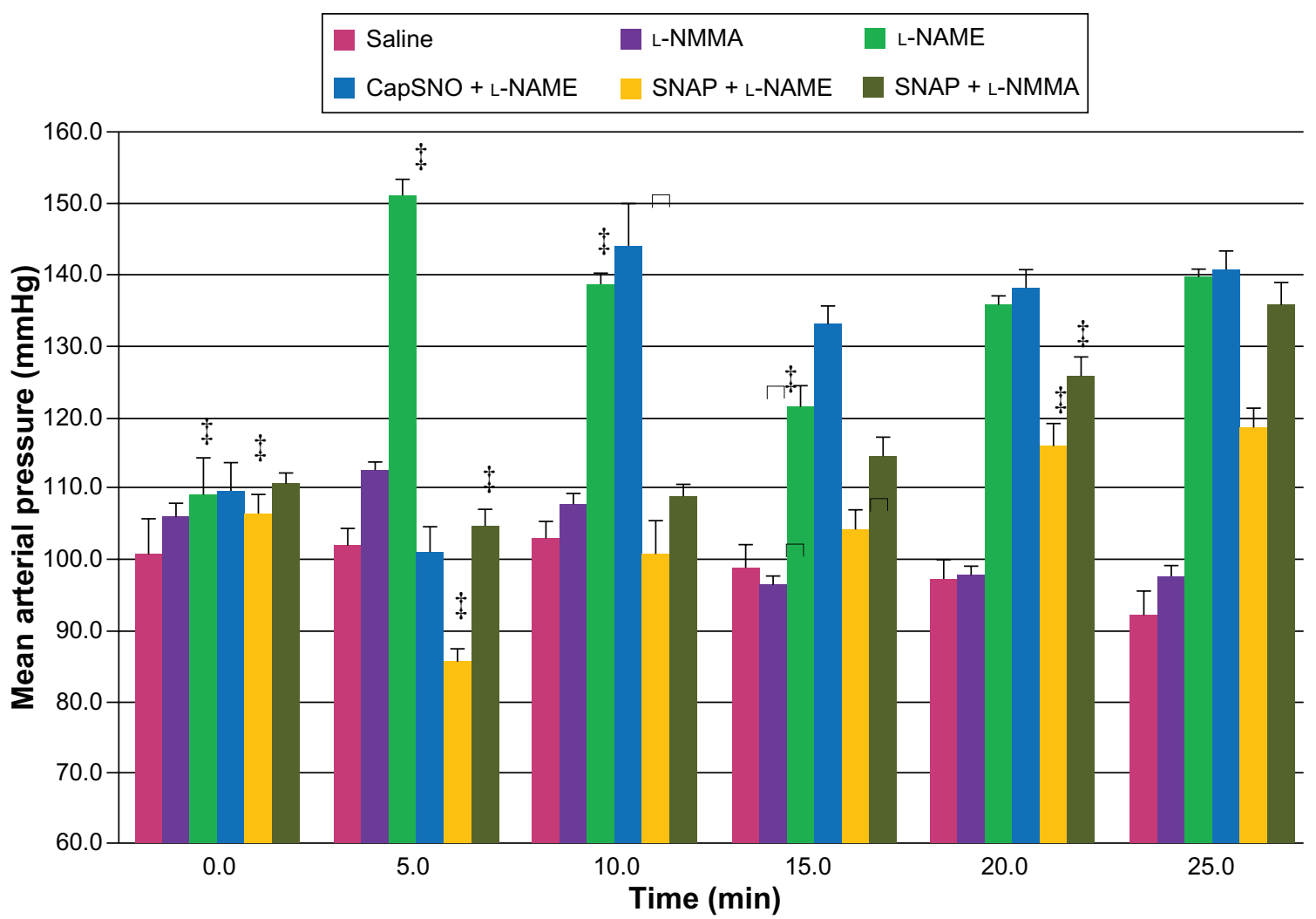

Figure 2 The effect of SNAP, CapSNO, L-NAME, and L-NMMA on mean arterial pressure.

Note: :Significant differences between values at time point given and $t=0$ or $t=5.0$ min; for full names of chemical compounds see Introduction.

In the present study, L-NMMA and L-NAME reversed the hypotension caused by SNAP and CapSNO. L-NMMA and L-NAME act by competitive inhibition of NO synthase and are firmly established to produce both acute and chronic hypertension in many animal species. ${ }^{23}$ Samsell et al found that arterial blood pressure increased $36 \%$ in rats on chronic administration of L-NAME and $37 \%$ in rats on L-NAME plus prazosin. ${ }^{24}$ The hypertensive response as observed by the elevated mean arterial pressure by L-NAME or L-NMMA administration could have been caused by a number of factors such as: i) decreasing the vasodilator effects of $\mathrm{NO}$ on the vasculature, or other hypertensive factors, normally attenuated by NO, ii) an enhanced response of the vascular smooth muscle to vasoconstrictors such as phenylephrine during the NO synthesis blockade, iii) a diminished vasodilator response of the vascular smooth muscle to endogenous dilators or exogenous NO donors such as SNAP or CapSNO, and iv) the release of endothelium-derived contracting factors. However, our data do not directly address these possibilities..$^{25-28}$

A key finding of the study is that while both NO inhibitors fully reversed the hypotensive effect of SNAP and CapSNO, L-NAME was more potent than L-NMMA in increasing blood pressure. Researchers have found that

Table 2 The effect of SNAP, CapSNO, L-NAME and L-NMMA on heart rate

\begin{tabular}{|c|c|c|c|c|c|c|}
\hline \multirow{2}{*}{$\begin{array}{l}\text { Time } \\
\text { (min) }\end{array}$} & \multirow[t]{2}{*}{ Saline } & \multicolumn{5}{|c|}{ Heart rate (beats min $^{-1}$ ) } \\
\hline & & L-NAME & L-NMMA & $\begin{array}{l}\text { CapSNO + } \\
\text { L-NAME }\end{array}$ & $\begin{array}{l}\text { SNAP + } \\
\text { L-NAME }\end{array}$ & $\begin{array}{l}\text { SNAP + } \\
\text { L-NMMA }\end{array}$ \\
\hline 0.0 & $327.00 \pm 6.62$ & $433.70 \pm 10.08$ & $411.68 \pm 12.72$ & $458.04 \pm 16.32$ & $486.60 \pm 30.82$ & $474.31 \pm 24.84$ \\
\hline 5.0 & $351.75 \pm 13.31$ & $362.46 \pm 15.81$ & $363.76 \pm 11.75$ & $466.87 \pm 14.77^{\ddagger}$ & $555.66 \pm 32.37^{\ddagger}$ & $479.53 \pm 5.40^{\ddagger}$ \\
\hline 10.0 & $352.25 \pm 15.12$ & $405.21 \pm 22.75$ & $382.22 \pm 17.89$ & $380.71 \pm 12.86$ & $570.84 \pm 40.07$ & $409.22 \pm 7.44$ \\
\hline 15.0 & $338.75 \pm 9.38$ & $389.35 \pm 24.08$ & $4 \mid 4.73 \pm 24.50$ & $355.07 \pm 9.52$ & $594.95 \pm 46.04$ & $411.06 \pm 15.24$ \\
\hline 20.0 & $344.50 \pm 4.25$ & $385.40 \pm 11.42^{\ddagger}$ & $406.64 \pm 19.26^{\ddagger}$ & $321.95 \pm 5.27$ & $576.26 \pm 50.37^{\ddagger}$ & $397.88 \pm 13.28 \neq$ \\
\hline 25.0 & $339.75 \pm 8.40$ & $391.39 \pm 11.69$ & $395.32 \pm 19.91$ & $336.90 \pm 17.48$ & $590.53 \pm 44.02$ & $363.33 \pm 9.51$ \\
\hline
\end{tabular}

Note: ₹Significant differences between values at time point given and $t=0$ or $t=5.0$ min; for full names of chemical compounds see Introduction. 
the blood pressure-raising effect of L-NAME was 2 to 3 times greater than that previously reported in similar studies using L-NMMA. ${ }^{27,29}$ One possible explanation is that human endothelial cells enzymatically degrade L-NMMA to L-arginine, which would oppose the pressor effect. ${ }^{30}$ Further, in normotensive human subjects, L-NAME acutely increased blood pressures into the hypertensive range. ${ }^{31}$ The largest effect of L-NAME was on DBP, which exceeded $85 \mathrm{mmHg}$ in $74 \%, 90 \mathrm{mmHg}$ in $52 \%$, and $100 \mathrm{mmHg}$ in $19 \%$ of subjects. DBP did not exceed $109 \mathrm{mmHg}$ in any subject, and in all subjects, blood pressure returned to baseline values by 24 hours without any deleterious side effects. $^{31}$

L-NAME causes acute vasoconstriction in a number of vascular beds and studies by Gardiner et al and Baylis et al showed that administration of L-NAME for several hours to conscious rats resulted in increases in arterial blood pressure. ${ }^{32,33}$ This NO inhibition in rats was associated with a decrease in cardiac output and blood flow to several vascular beds, and the bradycardia that accompanied the NO inhibition was reversed with atropine. ${ }^{32,34}$ These studies as well as results in this study suggest strongly that NO synthesis inhibition in the rat has marked effects on arterial blood pressure regulation for both short-term (minutes and hours) and long-term (days and weeks) periods. NO synthesis inhibitors have also been administered to conscious dogs by Persson et al who found that a single injection of L-NNA caused an increase in arterial blood pressure that lasted for 24 hours. ${ }^{35}$ The results of these studies differ from ours in the type of NO inhibitor used, and the concentrations of the NO inhibitors used in this study caused an effect which lasted for less than 1 hour.

An increase in sympathetic activity is another possible mediator of the increase in arterial blood pressure observed during the study due to L-NAME or L-NMMA administration. Sakuma et al showed that renal sympathetic nerve activity acutely increased after administration of L-NAME. ${ }^{25} \mathrm{NO}$ may act centrally to exert a tonic inhibitory influence on sympathetic nerve activity (SNA). Reduction in this tonic restraint has been postulated to contribute to the hypertension caused by synthetic NOS inhibitor. In addition, Pucci et al found that the pressor and renal vasoconstrictor effects of L-NAME were not impaired in anesthetized rats with blockade of either ganglionic transmission, $\alpha$-adrenergic receptors, arginine vasopressin, the renin-angiotensin system, or prostanoids. ${ }^{36}$ Therefore, whether increased sympathetic activity mediates part of the L-NAME pressor effect in the present study is not still clear. Further, in previous studies, intrarenal infusion of NO synthesis inhibitors induced potent renal vasoconstriction and anti-natriuresis. ${ }^{37} \mathrm{Liu}$ et al recorded renal SNA in conscious rabbits and found that intravenous L-NAME increased blood pressure and reflexively decreased renal SNA, whereas the return of blood pressure to baseline with hydralazine caused renal SNA to return to, but not exceed, baseline. ${ }^{37}$ This suggested that L-NAME alone did not exert sympathoexcitatory effects upon renal SNA. On the contrary, McKeogh et al suggested that the predominant effect of systemic NOS inhibition is to decrease SNA to both the heart and kidneys. ${ }^{38}$

The hypertension induced by L-NMMA and L-NAME was accompanied by bradycardia and the hypotension induced by SNAP or CapSNO was accompanied by tachycardia. A study by Manning and $\mathrm{Hu}$ showed that L-NAME caused significant decreases in the heart rate component of baroreceptor reflex sensitivity to nitroprusside. ${ }^{39}$ Studies have shown that NO donors directly (ie, independent of their effects on the autonomic nervous system) increase HR through a NO-cGMP-mediated stimulation of the pacemaker current $\mathrm{I}(\mathrm{f})$ in isolated sinoatrial node cells and spontaneously beating atrial preparations..$^{40,41}$ The direct positive chronotropic effect of exogenous NO is functionally relevant in vivo, both in animals ${ }^{42,43}$ and in humans. ${ }^{41}$ For instance, topical administration of SNP to the sinoatrial node in the pig heart in situ increases HR in the absence of changes in arterial blood pressure. ${ }^{42}$ Furthermore, intravenous infusion of SNP or molsidomine increases HR independent of autonomic activation in the rabbit ${ }^{43}$ and in humans when arterial blood pressure is clamped by simultaneous application of phenylephrine. ${ }^{44}$

In conclusion, the results demonstrate that SNAP and CapSNO reduced systolic, diastolic, and mean arterial pressures in rats. SNAP caused more significant decrease in blood pressure and was shown to be more potent than CapSNO. This hypotension was associated with an increase in heart rate. The data suggest that L-NAME and L-NMMA inhibit the action of NOS and that their action overrides the effect of NO released from SNAP or CapSNO. This may help to control blood pressure in hypertensive patients.

\section{Disclosure}

The authors have nothing to declare.

\section{References}

1. Stamler JS, Meissner G. Physiology of nitric oxide in skeletal muscle. Physiol Rev. 2001;81:209-237.

2. Alderton W, Cooper C, Knowles RG. Nitric oxide synthases: structure, function and inhibition. Biochem J. 2001;357:593-615. 
3. Kuo PC, Schroeder RA. The emerging multifaceted roles of nitric oxide. Ann Surg. 1995;221:220-235.

4. Wink DA, Miranda KM, Espey MG. Effects of oxidative and nitrosative stress in cytotoxicity. Semin Perinatol. 2000;24:20-23.

5. Mülsch A, Busse R. $\mathrm{N}^{\mathrm{G}}$-nitro-L-arginine ( $\mathrm{N}^{5}$-[imino(nitro amino) methyl]-L-ornithine) impairs endothelium-dependent dilations by inhibiting cytosolic nitric oxide synthesis from L-arginine. NaunynSchmiedebergs Arch Pharmacol. 1990;341:143-147.

6. Moore PK, Al-Swayeh OA, Chong NW, Evans RA, Gibson A. L- $\mathrm{N}^{\mathrm{G}}$-nitro arginine (L-NOARG) a novel, L-arginine-reversible inhibitor of endothelium-dependent vasodilatation in vitro. Br J Pharmacol. 1990;99:408-412.

7. Gardiner SM, Compton AM, Kemp PA, Bennett T. Regional and cardiac hemodynamic responses to glyceryl trinitrate, acetylcholine, bradykinin and endothelin-1 in conscious rats: effects of $\mathrm{N}^{\mathrm{G}}$-nitro-L-arginine methyl ester. Br J Pharmacol. 1990;101:632-639.

8. Gardiner SM, Kemp PA, Bennett T. Effects of NG-nitroL-arginine methyl ester on vasodilator responses to acetylcholine, $5^{\prime}$-Nethylcarboxamidoadenosine or salbutamol in conscious rats. $\mathrm{Br} J$ Pharmacol. 1991;103:1725-1732.

9. Vallance P, Collier J, Moncada S. Effects of endothelium-derived nitric oxide on peripheral arteriolar tone in man. Lancet. 1989;2:997-1000.

10. Rees DD, Palmer RMJ, Moncada S. Role of endothelium-derived nitric oxide in the regulation of blood pressure. Proc Natl Acad Sci U S A. 1989;86:3375-3378.

11. Ignarro LG, Buga GM, Wood KS, Byrns RE, Chaudhuri G. Endothelium-derived relaxing factor produced and released from artery and vein is nitric oxide. Proc Natl Acad Sci U S A. 1987;84 9265-9269.

12. McGowder D, Ragoobirsingh D, Dasgupta T. The hyperglycemic effect of S-nitrosoglutathione in the dog. Nitric Oxide. 1999;3:481-491.

13. Shaffer JE, Lee F, Thomson S, Ba-Jin H, Cooke JP, Loscalzo J. The hemodynamic effects of S-nitrosocaptopril in anesthetized dogs. J Pharmacol Exp Ther. 1991;256:704-710.

14. Lascalzo J, Smick D, Andon N, Cooke J. S-nitrosocaptopril: molecular characterization and effects on the vasculature and on platelets. J Pharmacol Exp Ther. 1988;249:726-729.

15. Nakae I, Takahashi M, Kinoshita T, Matsumoto T, Kinoshita M. The effects of s-nitrosocaptopril on canine coronary circulation. J Pharmacol Exp Ther. 1995;274:40-46.

16. McGrowder D, Ragoobirsingh D, Dasgupta T. Effects of s-nitroso-ncetylpenicillamine administration on glucose tolerance and plasma levels of insulin and glucagon in the dog. Nitric Oxide: Biol Chem. 2001;5:402-412.

17. Jia L, Blantz RC. The effects of S-nitrosocaptopril on renal filtration and blood pressure in rats. Eur J Pharmacol. 1998;354: 33-41.

18. Euser AG, Cipolla MJ. Cerebral blood flow autoregulation and edema formation during pregnancy in anesthetized rats. Hypertension. 2007; 49:334-340.

19. Cooke JF, Andon N, Loscalzo J. S-nitrosocaptopril II. Effects on vascular reactivity. J Pharmacol Exp Ther. 1989;249:730-734.

20. Henry PJ, Horwitz PJ, Louis WJ. Determinants of in vitro nitroglycerin tolerance induction and reversal: influence of dose regimen nitrate-free period, and sulfurhydryl supplementation. J Cardiovasc Pharmacol. 1989;14:31-37.

21. Ignarro LJ, Kadowitz PJ. The pharmacological and physiological role of cyclic GMP in vascular smooth muscle relaxation. Annu Rev Pharmacol Toxicol. 1985;25:171-191.

22. Ignarro LJ, Cirino G, Casini A, Napoli C. Nitric oxide as a signaling molecule in the vascular system: an overview. J Cardiovasc Pharmacol. 1999;34:879-886.

23. Aisaka K, Gross SS, Griffith OW, Levy R. $\mathrm{N}^{\mathrm{G}}$-methylarginine, an inhibitor of endothelium-derived nitric oxide synthesis, is a potent pressor agent in the Guinea pig: does nitric oxide regulate blood pressure in vitro? Biochem Biophys Res Commun. 1989;160: 881-886.
24. Samsell L, Engels K, Qui C, Baylis C. Combined angiotensin type 1 receptor (ATI) blockade with losartan (L) and a,-adrenoceptor blockade with prazosin $(\mathrm{P})$ normalize $\mathrm{BP}$ in chronic endothelial derived relaxing factor (EDRF) blockade induced hypertension (EB-HT). J Am Soc Nephrol. 1992;3:551. Abstract.

25. Sakuma I, Togashi H, Yoshioka M, et al. NG-methyl-Larginine, an inhibitor of L-arginine-derived nitric oxide synthesis, stimulates renal sympathetic nerve activity in vivo. A role for nitric oxide in the central regulation of sympathetic tone? Circ Res. 1992;70: $607-611$.

26. Moncada S, Rees DD, Schulz R, Palmer RMJ. Development and mechanism of a specific supersensitivity to nitrovasodilators after inhibition of vascular nitric oxide synthesis in vivo. Proc Natl Acad Sci U S A. 1991;88:2166-2170.

27. Haynes WG, Noon JP, Walker BR, Webb DJ. L-NMMA increases blood pressure in man. Lancet. 1993;342:931-932.

28. Luscher TF. Imbalance of endothelium-derived relaxing and contracting factors. A new concept in hypertension? Am J Hypertens. 1990;3: $317-330$.

29. Stamler JS, Loh E, Roddy MA, Currie KE, Creager MA. Nitric oxide regulates basal systemic and pulmonary vascular resistance in healthy humans. Circulation. 1994;89:2035-2040.

30. MacAllister RJ, Fickling SA, Whitley GS, Vallance P. Metabolism of methylarginines by human vasculature: implications for the regulation of nitric oxide synthesis. Br J Pharmacol. 1994;112:43-48.

31. Sander M, Chavoshan B, Victor RG. A large blood pressure-raising effect of nitric oxide synthase inhibition in humans. Hypertension. 1999; 33;937-942.

32. Gardiner SM, Compton AM, Kemp PA, Bennett T. Regional and cardiac haemodynamic effects of NG-nitro-L-arginine methyl ester in conscious, Long Evans rats. Br J Pharmacol. 1990;101: 625-631.

33. Baylis C, Harton P, Engels K. Endothelial derived relaxing factor controls renal hemodynamics in the normal rat kidney. J Am Soc Nephrol. 1990;1:875-881.

34. Chen HI, Chapleau MW, McDowell TS, Abboud FM. Prostaglandins contribute to activation of baroreceptors in rabbits: possible paracrine influence of endothelium. Circ Res. 1990;67:1394-1404.

35. Persson PB, Baumann JE, Ehmke H, Nafz B, Wittmann U, Kirchheim HR. Phasic and 24-h blood pressure control by endothelium-derived relaxing factor in conscious dogs. Am J Physiol. 1992;262:H1395-H1400.

36. Pucci ML, Lin L, Nasjletti A. Pressor and renal vasoconstrictor effects of $\mathrm{N}^{\mathrm{G}}$-nitro-L-arginine as affected by blockade of pressor mechanisms mediated by the sympathetic nervous system, angiotensin, prostanoids and vasopressin. J Pharmacol Exp Ther. 1992;261: 240-245.

37. Liu JL, Murakami H, Zucker IH. Angiotensin II-nitric oxide interaction on sympathetic outflow in conscious rabbits. Circ Res. 1998;82: 496-502.

38. McKeogh DF, O'Donaughy TL, Brooks VL. NO and endogenous angiotensin II interact in the generation of renal sympathetic nerve activity in conscious rats. Am J Physiol Heart Circ Physiol. 2004;286: H1258-H1265.

39. Manning RD, Hu L. Cardiovascular-renal responses to long-term nitric oxide inhibition during angiotensin II-AT1 receptor inhibition. Am J Hypertens. 1998;11:328-339.

40. Musialek P, Lei M, Brown HF, Paterson DJ, Casadei B. Nitric oxide can increase heart rate by stimulating the hyperpolarization-activated inward current, I(f). Circ Res. 1997;81:60-68.

41. Musialek P, Paterson DJ, Casadei B. The chronotropic response to nitric oxide in the isolated guinea-pig atria is not affected by $\beta$-adrenergic blockade. J Physiol. 1997;504P:83.

42. Musialek P, Nash M, Thornton J, Casadei B, Paterson DJ. The nitric oxide donor sodium nitroprusside increases heart rate in the absence of changes in arterial blood pressure when applied topically to the sinoatrial node in the anaesthetised pig. J Physiol. 2000;523P: $267-268$. 
43. Hogan N, Casadei B, Paterson DJ. Nitric oxide donors can increase heart rate independent of autonomic activation. J Appl Physiol. 1999; 87:97-103.
44. Hogan N, Kardos A, Paterson DJ, Casadei B. Effect of exogenous nitric oxide on baroreflex function in humans. Am J Physiol. 1999;277:H221-H227.

\section{Publish your work in this journal}

Open Access Animal Physiology is an international, peer-reviewed, open access journal publishing original research, reports, reviews and commentaries on all areas of animal physiology. The manuscript management system is completely online and includes a very quick and fair peer-review system. Visit http://www.dovepress.com/ testimonials.php to read real quotes from published authors. 